
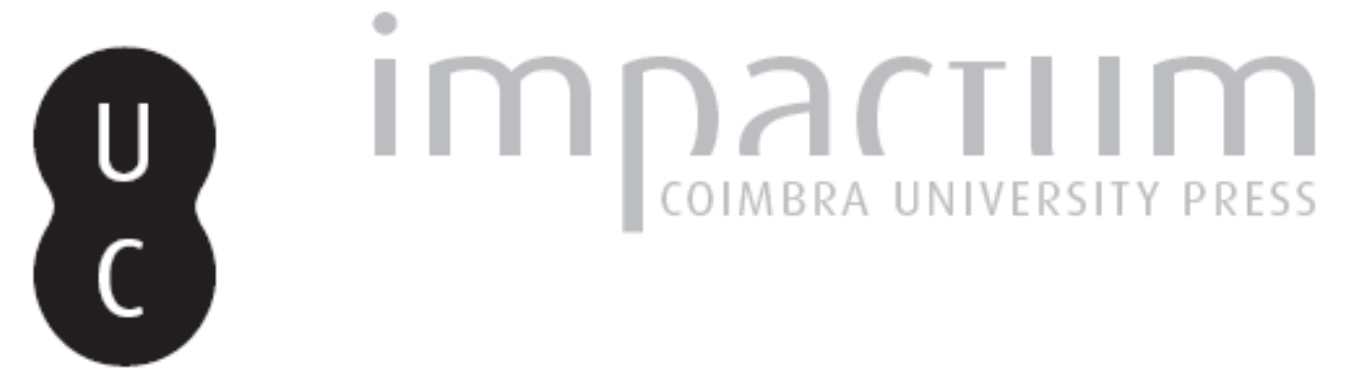

\title{
Albert Camus ou a experiência do jornalismo crítico
}

Autor(es): Mesquita, Mário

Publicado por: Imprensa da Universidade de Coimbra

URL persistente:

URI:http://hdl.handle.net/10316.2/36943

DOI:

DOI:http://dx.doi.org/10.14195/2183-6019_1_8

Accessed : $\quad$ 26-Apr-2023 12:12:23

A navegação consulta e descarregamento dos títulos inseridos nas Bibliotecas Digitais UC Digitalis, UC Pombalina e UC Impactum, pressupõem a aceitação plena e sem reservas dos Termos e Condições de Uso destas Bibliotecas Digitais, disponíveis em https://digitalis.uc.pt/pt-pt/termos.

Conforme exposto nos referidos Termos e Condições de Uso, o descarregamento de títulos de acesso restrito requer uma licença válida de autorização devendo o utilizador aceder ao(s) documento(s) a partir de um endereço de IP da instituição detentora da supramencionada licença.

Ao utilizador é apenas permitido o descarregamento para uso pessoal, pelo que o emprego do(s) título(s) descarregado(s) para outro fim, designadamente comercial, carece de autorização do respetivo autor ou editor da obra.

Na medida em que todas as obras da UC Digitalis se encontram protegidas pelo Código do Direito de Autor e Direitos Conexos e demais legislação aplicável, toda a cópia, parcial ou total, deste documento, nos casos em que é legalmente admitida, deverá conter ou fazer-se acompanhar por este aviso.

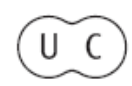


revista de comunicação,

jornalismo e espaço público

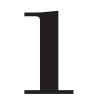

Periodicidade

Semestral

Imprensa da Universidade de Coimbra Coimbra University Press

\section{mediapolis}

os media e a construção

de personagens

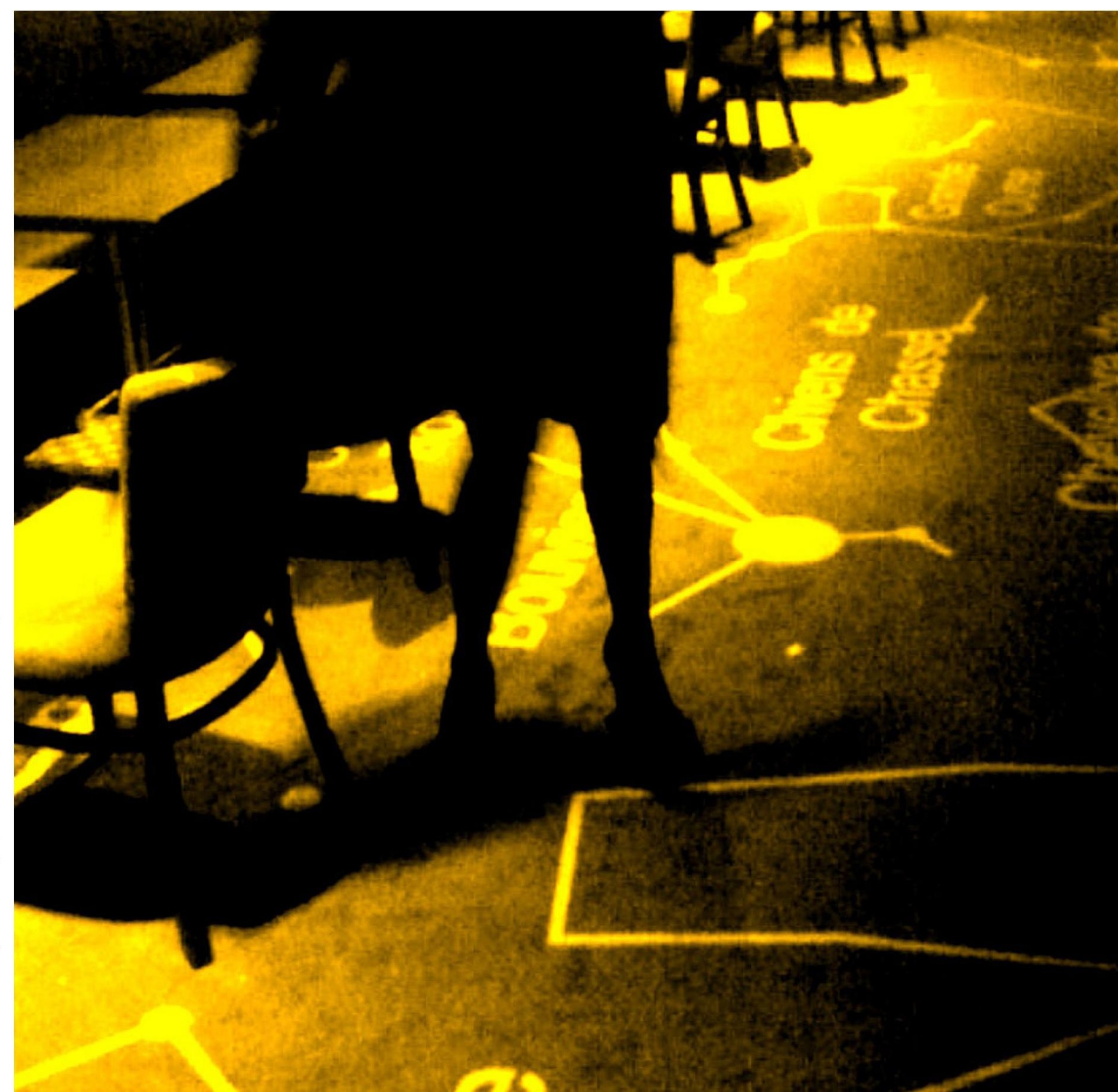




\section{Albert Camus ou a experiência do jornalismo crítico}

Resumo

Mário Mesquita fala-nos neste texto de um jornalismo utópico: um jornalismo crítico, liberto dos interesses da política e do dinheiro, inserido no campo da cultura, capaz de se pôr em causa e profundamente empenhado com a democracia. Um jornalismo que Albert Camus assumiu sem ilusões, mas que acabou por considerar uma das mais belas profissões do mundo. Escritor, antes mesmo de ser o jornalista que não enjeitou iniciar-se pelas tarefas básicas de estagiário na redação do Combat, e inteletual: Camus nunca foi um homem de conformismos nem na literatura, nem no pensamento, nem no jornalismo, facto que lhe valeu o isolamento na intelectualidade francesa. Muito para além do opinionmaker dos nossos dias, ele foi o intelectual com a coragem moral da opinião diferente e livre. Palavras de Mário Mesquita a propósito do centenário do nascimento de Albert Camus e dos 20 anos da Licenciatura em Jornalismo da Universidade de Coimbra.

Palavras-Chave: Camus, jornalismo crítico, Combat, intelectual.
Abstract

Mário Mesquita speaks of a utopian journalism: a critical journalism, free of the interests of politics and money, inserted in the field of culture, able to undermine itself and deeply committed to democracy. A Journalism that Albert Camus took with no illusions, but turned out to consider one of the most beautiful professions in the world. Writer, even before journalist, who did not reject to start the basic tasks of an intern in the newsroom of the Combat, and intellectual: Camus was never a man of conformism in literature, neither in thought nor in journalism, fact that explains its isolation in the French intellectuality. Well beyond the opinion maker of our days, he was the intellectual with the moral courage of free and different opinion. Mario Mesquita's words concerning the centenary of the birth of Albert Camus in the 20 years of the Degree in Journalism in the University of Coimbra.

Keywords: Camus, critical journalism, Combat, intelectual. 
Albert Camus não escolheu o jornalismo por vocação. À semelhança de tantos outros, foram as necessidades de subsistência a determinar que, além de escritor, pensador e dramaturgo, fosse também jornalista. Por motivos relacionados com mercados de leitura, que variam de país para país, os escritores acumulam, por via de regra, pelo menos durante algum tempo, duas ou mais profissões.

Não está em causa apenas a questão do "segundo ofício", conforme explica o sociólogo Bernard Lahire, mas o problema "mais complexo" da "dupla vida" dos escritores (Lahire, 2006: 19), na medida em que essa outra atividade profissional lhes condiciona o quotidiano e lhe proporciona novas experiências e constrangimentos.

Entre os segundos ofícios mais frequentes encontram-se funções como as ligadas ao ensino, ao jornalismo ou à edição, mas, por exemplo, no nosso país - onde escasseiam as condições de subsistência material - escritores, médicos, advogados ou publicitários, também se dedicaram à criação literária. No caso do jornalismo colocam-se, por vezes, as questões relacionadas com a gestão de possíveis "conflitos de estilo de escrita (literária e jornalística)" (Lahire, 2006: 275), sobretudo quando está em causa a linguagem da informação condicionada, desde o telégrafo ao digital, pelas tecnologias que a moldam e pelos diversos públi$\cos$ que visa atingir.

Aos 25 anos, Albert Camus aceitou o convite do seu amigo Pascal Pia para redator do Alger Républicain, jornal de esquerda, próximo da Frente Popular. Não nutria ilusões sobre a profissão, que considerava um "ofício dececionante", embora capaz de proporcionar "uma sensação de liberdade" (Todd, 1996: 243). Mas quem o convidou para o diário entendia que Camus possuía a capacidade, o estilo e o "sentido de encenação do bom repórter".

Desta forma, Camus começou a sua aprendizagem - já com dois livros publicados - pelas tarefas básicas do estagiário: os crimes, os acidentes, os necrológios e os processos judiciais, todo esse mundo de ocorrências transformadas em notícias que, sendo consideradas tarefas menos nobres, ligam o jornal ao quotidiano das cidades (Robert Park, Michael Schudson). As suas reportagens sobre a pobreza e o sofrimento da população árabe - um povo com três séculos de atraso, no seu próprio dizer - ficaram célebres e integram hoje as obras completas da Pléiade. Não foi apenas colunista ou colaborador da imprensa, como tantos outros escritores célebres do seu tempo, de Sartre a Mauriac. Trilhou o percurso habitual de qualquer aprendiz da profissão pelo caminho do fait divers que substitui nas grandes cidades o rumor das aldeias.

Durante alguns anos da sua vida, em Argel (1937-40) e em Paris (194447), retirou da imprensa o seu principal meio de subsistência. Não usou apenas os jornais como um lugar de expressão de intelectual público, empenhado nas grandes causas públicas do seu tempo, desde a questão argelina, à crítica dos diversos totalitarismos. Aderiu por inteiro a essa profissão que, de início, não o atraía. Porque vivemos num tempo em que o jornalismo nas suas diferentes formas, parece afastar-se cada vez mais do modelo exigente proposto e praticado por Camus, faz todo o sentido evocar a sua intervenção jornalística.

O seu excecional biógrafo Olivier Todd conta que, no imediato pósGuerra, já consagrado como escritor 
Propor o

\section{"jornalismo}

crítico" de Albert

Camus como

modelo para

os nossos dias

é seguramente

utópico
- com a publicação de $O$ Estrangeiro

- Camus entra, de novo a convite de Pascal Pia, na redação de Combat, diário fundado por um grupo da resistência à ocupação alemã, ainda na clandestinidade. Aceita o novo desafio - nas palavras de Todd - "não só para desenvolver ideias, mas também porque gosta desse meio" onde reencontra "o trabalho de equipa e o jornalismo, droga doce e dura" (Todd, 1996: 494). O romancista cultiva as relações, não só com os colegas redactores e repórteres, mas também com os revisores e os tipógrafos, ainda ao tempo da composição a chumbo, "espécie de aristocracia operária, corporativista, consciente das suas qualidades e dos seus privilégios" (Todd, 1996: 495).

Era um jornal pluralista, difícil de caracterizar pela diversidade dos seus colaboradores, na sua maior parte de esquerda não-comunista, mas que se iriam dividir, antes do final dos anos 40, com alguns deles, entre os quais o diretor, Pascal Pia, a aproximaremse do General De Gaulle e outros, à semelhança de Camus, à procura do oximoro do socialismo em liberdade. Por diferentes motivos, Albert Camus e Pascal Pia afastaram-se do projeto.
O jornal perdeu o brilho e a inspiração iniciais, mas com novas direções e menor sucesso Combat permaneceu na paisagem jornalística francesa até 1974. Bem tinha avisado Pascal Pia, logo no início da experiência: "Vamos tentar fazer um jornal razoável, mas, como o mundo é absurdo, ele vai falhar".

Apesar disso, o jornal foi, nos primeiros três anos, um êxito, com uma tiragem média diária de 122 mil exemplares em 1947, quando o "popular" France-Soir atingia 578 mil exemplares e o Le Monde 174 mil (Bellanger et al. 1958, 357). Todd lembra que Camus já "era conhecido como escritor", mas "com os seus artigos do Combat transforma-se num jornalista célebre. Enquanto romancista atingia alguns milhares de leitores. Como editorialista influencia várias centenas de milhares de franceses".

Entre 1944 e 1947, Camus acumula três profissões: escritor, jornalista e membro do comité de leitura da Gallimard. O interesse do seu regresso às redações não resulta apenas dessa notoriedade suplementar, que bem poderia ter dispensado, mas do projeto de criar um novo jornalismo 
saído do "espírito da Resistência”, em nítida rotura com a imprensa da $\mathrm{III}^{\mathrm{a}}$ República que considerava enfeudada aos interesses da política e do dinheiro. No primeiro editorial do Combat, enquanto órgão legal, escreve: “O nosso desejo, tanto mais profundo quanto por vezes era mudo, consistia em libertar os jornais do dinheiro e de lhes dar um tom e uma verdade que coloquem o público à altura daquilo que nele há de melhor" (Lévi-Valensi (org.), 2002: 160).

O mesmo Camus que, nos anos 30, menosprezava o jornalismo, vai designá-lo, passada mais de uma década, como "uma das mais belas profissões que conhece"1. Porquê? O melhor é reter a opinião do próprio escritor: "o jornalismo exige que os jornalistas se ponham em questão a si próprios" (Malye, 2013 : 70). Mas, à luz desta exigência, a forma como a imprensa se reconfigurava após a libertação de Paris constituía para Camus uma desilusão. A cedência às exigências comerciais era sempre justificada da mesma forma: "É isto o

1 Em entrevista à revista Caliban, em 1951 (apud Malye, 2013 : 70). que o público quer". Mas para o autor de L'Étranger não era isso o que o público queria, mas sim aquilo que lhe ensinavam a querer. E argumentava: "se vinte jornais, todos os dias do ano, criam à sua volta o mesmo ambiente de mediocridade e de artifício, ele (público) respirará nesse ambiente e terá dificuldade em dispensá-lo" (Lévi-Valensi (org.), 2002: 165).

Dirigido por Pascal Pia e Albert Camus, o diário Combat deixará uma marca forte na história da imprensa francesa que se deve à prática daquilo a que Camus chamava o "jornalismo crítico". Tal prática distinguia-se do jornalismo partidário ou comercial. A esse tipo de jornalismo exigia-se uma relação ao leitor. Explica Camus: "Em face das forças desordenadas da história, que têm nas informações o seu eco, pode ser positivo anotar, dia a dia, a reflexão de um espírito ou as observações comuns a diversos espíritos. Mas isso não pode ser feito sem escrúpulos, sem distância e sem uma certa ideia do relativo (...)" (Lévi-Valensi (org.), 2002: 181).

Esta ideia está intimamente ligada à relação que Camus estabelece entre "Democracia e Modéstia" porque o democrata define-se, entre outros predicados, por admitir "que um adversário pode ter razão" e, portanto, o "deixa exprimir-se e aceita refletir acerca dos seus argumentos". Essa modéstia praticava-se dentro do próprio jornal, através da diversidade dos colaboradores, mas até nos textos do próprio Camus que enunciava na primeira pessoa do plural as atitudes comuns a toda a equipa do jornal e na primeira pessoa do singular os artigos que refletiam a sua própria visão.

Vários dos seus editoriais de Combat ficaram célebres, desde o seu editorial angustiado aquando da bomba atómica de Hiroshima, as discordâncias sobre os muito incertos rumos da depuração política francesa, a oposição à tolerância das democracias vencedoras da Guerra com a ditadura de Espanha franquista, em nome da realpolitik da Guerra Fria, o silêncio de certos intelectuais perante as atrocidades da URSS, justificado em nome das injustiças do capitalismo ou a análise da vida de Roosevelt na perspetiva da luta contra a doença, experiência similar à do próprio Camus (com a tuberculose). 
Em 1947, quando abandona a redação de Combat, Albert Camus já deixou demarcado o território que conduziria, aquando da publicação do ensaio L'Homme Revolté, à rotura com Sartre e o grupo da revista Les Temps Modernes. Reformista, democrata da esquerda moderada, desiludido com os socialistas da $\mathrm{SFIO}^{2}$, enredados nas malhas do colonialismo argelino, Camus ficaria, ao longo da década de 50, mais e mais isolado na intelectualidade francesa. Ostracizado pelas tendências marxistas, enquanto, à direita, Raymond Aron e outros o tratavam com quase humilhante condescendência.

Volta à imprensa, nas páginas do magazine L'Express (1955-56), para defender, ao lado de François Mauriac, uma solução moderada, quiçá utópica, para a Argélia, que poderia ter sido executada pela figura excecional de Pierre Mendès-France. Mas a revista de Servan-Schreiber e Françoise Giroud, moldada pelo modelo norte-americano da Time, não era o

2 Section Française de l'Internationale $\mathrm{Ou}$ vrière, liderada por Guy Mollet. Transformou-se, na década de 70, no atual Partido Socialista. seu meio, nem possuía um ambiente jornalístico semelhante ao de Combat. A crença numa possível conciliação entre franceses e árabes da Argélia parecia tardia e utópica. No final dos anos 50, acabaria por lhe concitar, em simultâneo, o ódio dos colonialistas da Organisation Armée Secrète ${ }^{3}$ (OAS) e da esquerda radical apoiante da FNL e dos métodos de terrorismo a que o movimento nacionalista recorreu. Os louros do Prémio Nobel que the foi outorgado em 1957, longe de contribuírem para a sua tranquilidade em França ou na Argélia, vieram intensificar as polémicas à sua volta. Os mecanismos da "espiral do silêncio"4 criaram um certo vazio à volta.

Numa conferência de imprensa em Estocolmo, Camus dirá: "Sempre condenei o terror. Tenho de condenar igualmente um terrorismo que se

3 A Organisation Armée Secrète, também conhecida pela sigla OAS, foi criada em Madrid em 11 de fevereiro de 1961 e defendia a manutenção da presença francesa na Argélia, a todo o custo e recorrendo a todos os meios necessários, inclusivamente o terrorismo.

4 Do livro de Noel-Neumann, La Espiral del Silencio. Veja-se, em especial o capítulo "Vanguardistas, hereges y disconformes: los desafiantes de la opinión pública" (NoelleNeumann, 1995: 183-187). exerce às cegas, nas ruas de Argel por exemplo, e que um dia pode atingir a minha mãe ou a minha família. Acredito na justiça, mas defenderei a minha mãe antes da justiça". Isolada do contexto, a última frase permitiu toda a espécie de especulações filosóficas ou pseudo-filosóficas (Froloff, 2009: 613).

Propor o "jornalismo crítico" de Albert Camus como modelo para os nossos dias é seguramente utópico. Basta olhar à volta da nossa paisagem mediática - e não só a portuguesa... - para se verificar que será muito difícil que nele desempenhe papel de relevo um intelectual que preza um certo relativismo, acredita nas virtudes da dúvida, defende a autonomia dos jornalistas e outros atores do debate público (Guerin, 2009; 420). Ao tempo de Camus, como escreve Milan Kundera, "o jornalismo não era ainda classificado, fora da cultura, nessa categoria a que se chama hoje 'os media"" (Kundera, 2003: 104-105).

A intervenção pública de Albert Camus situava-se nos antípodas do ultrapassado conceito de opinionmaker ou dos conselheiros e especialistas integrados em think tanks, ao serviço 
de governos, partidos ou grupos de pressão. Para terminar esta palestra em homenagem a um escritor e jornalista franco-argelino, afiguram-se adequadas estas palavras de Tony Judt: “a coragem moral necessária para ter uma opinião diferente e impô-la a leitores irritados ou ouvintes insensíveis continua em todo o lado a ser pouca" (Judt, 2010: 155).

\section{Bibliografia:}

LAHIRE, B. (2006). La Condition Littéraire - la double vie des écrivains. Paris : Éditions de la Découverte TODD, O. (1996). Camus, Une Vie. Paris: Gallimard.

BELLANGER, C. (et al.), (1975). Histoire Générale de la Presse Française, Tome I: de 1940 à 1958. Paris: Presses Universitaires de France.

LÉVI-VALENSI, J. (org.) (2002). Cahiers Albert Camus: Camus à Combat. Paris: Gallimard.

MALYE, F. (2013). Le Point (hors-série, numéro 15), oct.-nov.

NOELLE-NEUMANN,E.(1995). La Espiral del Silencio. Barcelona: Paidós, Comunicación.
FROLOFF, N. (2009). "Nobel, Prix". In: Guérin, J. (org.), Dictionnaire Albert Camus. Paris: Robert Lafont.

GUÉRIN, J. (2009). "Intellectuel”. In: Guérin, J. (org.), Dictionnaire Albert Camus. Paris: Robert Lafont, p. 420

KUNDERA, M. (2003). "Le greffier de l'ephémère". In: Daniel, J., Observateur du Siècle. Paris: BNF/Saint-Simon.

JUDT, T. (2010). Um Tratado Sobre os Nossos Actuais Descontentamentos. Lisboa: Edições 70. 